\title{
ISCEV extended protocol for the S-cone ERG
}

\author{
Ido Perlman (iD) - Mineo Kondo • Enid Chelva • Anthony G. Robson • \\ Graham E. Holder
}

Received: 30 September 2019/Accepted: 4 October 2019/Published online: 20 November 2019

(C) The Author(s) 2019

\begin{abstract}
The International Society for Clinical Electrophysiology of Vision (ISCEV) standard for full-field electroretinography (ERG) describes a minimum procedure for testing generalized retinal function but encourages more extensive testing. This extended protocol describes a method of assessing the function of the short-wavelength-sensitive cone (Scone) retinal pathway, using a short-wavelength flash superimposed on a background that saturates the rods and adapts the L/M-cones to elicit a response, known as the S-cone ERG. Stimulus parameters such as the strength and luminance of the flash and background, respectively, and their spectral and temporal characteristics are specified. As a complement to the ISCEV standard, testing the S-cone ERG enables further characterization of light-adapted retinal function and
\end{abstract}

I. Perlman $(\bowtie)$

Ruth and Bruce Rappaport Faculty of Medicine,

Technion-Israel Institute of Technology, Haifa, Israel

e-mail: iperlman@technion.ac.il

I. Perlman

Division of Ophthalmology, Tel Aviv Sourasky Medical

Center, Tel Aviv, Israel

M. Kondo

Department of Ophthalmology, Mie University Graduate

School of Medicine, Tsu, Japan

E. Chelva

Department of Medical Technology and Physics, Sir

Charles Gairdner Hospital, Nedlands, Australia may refine diagnosis of some retinal disorders. Typical applications are described including use in the diagnosis of rod monochromacy and S-cone monochromacy, identification and investigation of cone Onbipolar cell dysfunction and use of the technique to confirm the diagnosis of enhanced S-cone syndrome.

Keywords Clinical standards $\cdot$ Electroretinogram (ERG) · Full-field ERG · International Society for Clinical Electrophysiology of Vision (ISCEV) · Scone ERG · Short-wavelength-sensitive cone ERG · Retinopathy $\cdot$ Retinal dystrophy
A. G. Robson
Moorfield Eye Hospital and Institute of Ophthalmology,
University College London, London, UK
G. E. Holder
National University of Singapore, Singapore, Singapore
G. E. Holder
UCL Institute of Ophthalmology, London, UK 


\section{Introduction}

The International Society for Clinical Electrophysiology of Vision (ISCEV) standard for full-field electroretinography (ERG) describes a minimum procedure for testing generalized retinal function but encourages more extensive testing [1]. This extended protocol describes a method of assessing the function of the short-wavelength-sensitive cone (S-cone) retinal pathway, using a short-wavelength flash superimposed on a background light to elicit a response, known as the S-cone ERG. The S-cone ERG is a specialized procedure which is well established and broadly accepted by experts in the field. The protocol was prepared by the authors in accordance with ISCEV procedures (http://www.iscev.org/standards/ index.html) and approved by the ISCEV Board of Directors on September 23rd, 2019.

\section{Scope and application}

The ISCEV standard ERGs are recorded under darkadapted (DA) and light-adapted (LA) conditions to assess both rod and cone system functions. The standard LA ERGs are normally dominated by responses driven by the long-wavelength-sensitive cones (L-cones) and medium-wavelength-sensitive cones (M-cones). There are far fewer short-wavelength-sensitive cones (S-cones) than L/M-cones, and their summed responses to light are of smaller amplitude and slower kinetics. Therefore, the S-conemediated retinal activity is not directly visible in the standard LA ERGs. This extended protocol describes parameters for the recording of the S-cone ERG, reflecting the activity of the S-cone pathways in the distal retina. The S-cone ERG is elicited using shortwavelength (blue) flashes on a long-wavelength background to saturate the rod system and to reduce contributions from the L/M-cone systems [2-4]. The ERGs to such stimuli normally vary in waveform shape according to flash strength. To dim stimuli, there is typically a single low-amplitude component of relatively long peak time (Fig. 1). To stronger flashes, an additional earlier peak occurs and grows with increasing flash strength. The action spectrum of the 1 st peak has a maximum at $520 \mathrm{~nm}$ and that of the $2 \mathrm{nd}$ peak at $450 \mathrm{~nm}$ [3]. In S-cone monochromacy, there is a later peak only [3], whereas in tritanopia there may be a normal 1st peak and a very small 2nd peak [4]. These and other studies are consistent with response contributions from the L/M-cone system to the first peak and the S-cone system to the second peak.

The addition of S-cone ERG testing to the standard ERG protocol enables further characterization of LA retinal function and can help in determining the origin of abnormal standard ERGs. Typical clinical applications of S-cone ERGs are outlined below:

a. In inherited retinal disorders, a more detailed knowledge of the phenotype may refine the diagnosis and facilitate mutational screening. It can confirm the origins of the recorded signals in enhanced S-cone syndrome (ESCS) consequent upon mutation in NR2E3 gene after the pathognomonic features have been revealed with conventional ISCEV standard ERG testing [5, 6]. Mutations in the NRL gene, the upstream gene to NR2E3, also cause a retinal phenotype similar to ESCS, but not identical in all ERG features [7, 8].

b. S-cone ERG recording is important in the distinction between rod monochromacy and S-cone monochromacy. In both disorders, the rod-driven ERG components are normal or well-preserved. The LA 3.0 ERG is usually undetectable in rod monochromacy, but in S-cone monochromacy may be detectable as a small amplitude b-wave of long implicit time appearing at approximately $50 \mathrm{~ms}$, suggestive of an S-cone system origin that can be more accurately confirmed by S-cone ERG recording [2]. S-cones, like rods, transmit signals via an On-bipolar cell pathway, and any disorder affecting global retinal On-pathway function, such as "complete" CSNB (congenital stationary night blindness), will have reduced S-cone ERGs [9].

c. Inherited tritanopia is rare, and such patients cannot be identified with Ishihara plates, but only by testing color vision in the tritan color confusion axis (e.g., HRR plates, Farnsworth-Munsell 100-Hue, L'Anthony D15, color contrast sensitivity, etc.). Although many patients with tritanopic defects may have normal S-cone ERGs, some patients show S-cone ERG abnormalities [4].

d. Elevated tritan thresholds can also occur in acquired disorders associated with reduction in S-cone pathway function. Examples include melanoma-associated retinopathy, characterized 


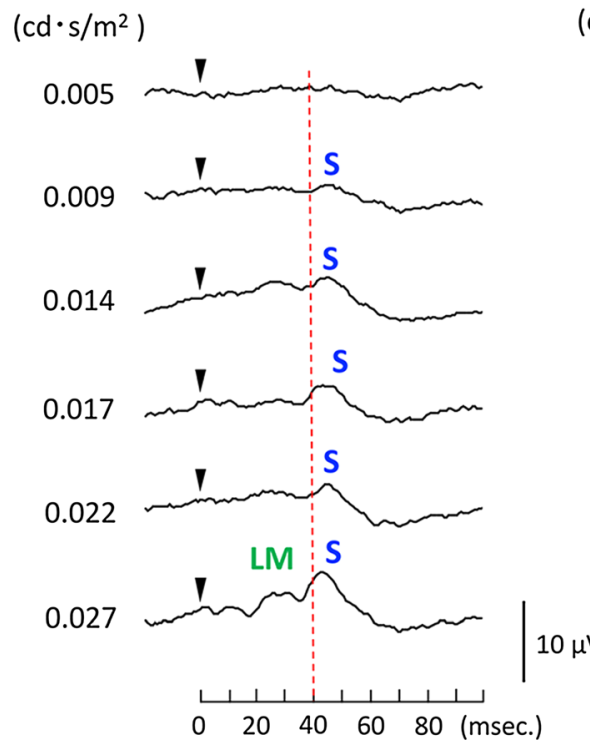

Fig. 1 Stimulus-response series of the S-cone ERG recorded from a control subject using a Burian-Allen corneal electrode. An LED system was used to generate a $1 \mathrm{~ms}$ blue ( $450 \mathrm{~nm}$ halfheight bandwidth $20 \mathrm{~nm}$ ) full-field flash, superimposed on a yellow $(570 \mathrm{~nm})$ background (luminance $300 \mathrm{~cd} \mathrm{~m}^{-2}$ ). The stimulus frequency was $4.5 \mathrm{~Hz}$. In this case, $300-500$ responses were averaged. At low stimulus strengths (approximately of

by ERGs indistinguishable from those in complete congenital stationary night blindness, and reflecting On-bipolar cell dysfunction. Tritan defects may also occur in vitamin A deficiency, where some patients report seeing "white as green" as a result of loss of S-cone function, and in diabetes. The recovery of S-cone function following vitamin A supplementation can be monitored with S-cone ERGs [10].

\section{Patient population}

Patients of all ages, able to tolerate Ganzfeld stimulation, referred for investigation of possible retinal dysfunction, retinal dystrophy, generalized cone or rod system dysfunction or patients with photophobia and/ or nystagmus may benefit from the S-cone ERG, performed in addition to the ISCEV standard ERG.

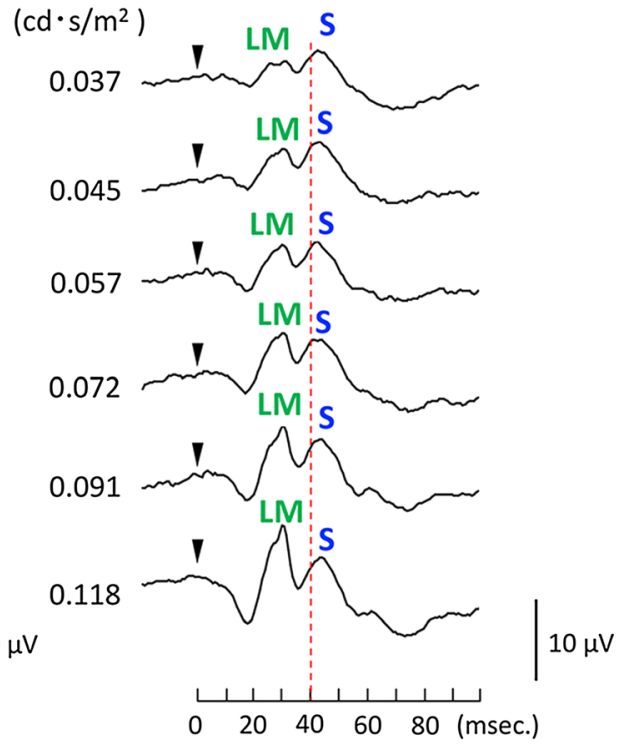

$0.01-0.02 \mathrm{~cd} \mathrm{~s} \mathrm{~m}^{-2}$ ), single positive $\mathrm{S}$-cone responses are observed. At moderate and high stimulus strengths (approximately $0.025-0.12 \mathrm{~cd} \mathrm{~s} \mathrm{~m}^{-2}$ ), two positive peaks are seen, the first (at approx. $30 \mathrm{~ms}$ ) reflects activity of the L/M-cone system and the second (at approx. $40 \mathrm{~ms}$ ) is the S-cone-mediated ERG component. Red dotted lines are drawn at $40 \mathrm{~ms}$

\section{Technical issues}

S-cone ERG recording is performed following the specifications of the current ISCEV standard for fullfield ERG [1]. Recordings of the S-cone ERG can be embedded within the standard protocol [1] or conducted as a separate protocol. Additional factors are outlined below:

a. Spectral characteristics and luminance of the background

The photopic background for the recording of the S-cone ERG must be of spectral composition and strength that will achieve two goals: (1) saturate the rod system and (2) minimize the contributions of the L/M-cones systems. The initial studies used a white background, but later studies and the developments of new electrophysiology of vision systems indicated that bright LEDs with spectral peaks between 570 and $620 \mathrm{~nm}$ (yellow, amber, orange) were more suitable for the purpose of obtaining an S-cone ERG (Table 1). A high background luminance of appropriate wavelength may optimize isolation of S-conemediated responses, but patient comfort, tolerance and 
the possibility of photophobia must also be considered.

b. Spectral characteristics of the test flash

Short-wavelength (blue) stimuli may be generated using Xenon light in combination with a suitable optical filter (Kodak \#98, having a peak transmission at $450 \mathrm{~nm}$ ) or by using a light emitting diode (LED) with a peak output of short wavelength, in the region of 440-470 nm (Table 1). Wavelengths longer than $470 \mathrm{~nm}$ typically generate ERGs that are dominated by the L/M-cones, and the contribution of the S-cones to the ERG may not be detectable. Light sources with wavelength shorter than $440 \mathrm{~nm}$ may not have sufficient strength to elicit a reliable S-cone ERG because the S-cone ERG action spectrum peaks at $450 \mathrm{~nm}$ [3].

Table 1 Stimulus and background conditions for recording S-cone ERG

\begin{tabular}{|c|c|c|c|c|c|}
\hline References & Stimulus wavelength & Stimulus strength & $\begin{array}{l}\text { Rate of } \\
\text { stimulus } \\
(\mathrm{Hz})\end{array}$ & $\begin{array}{l}\text { Background } \\
\text { wavelength }\end{array}$ & $\begin{array}{l}\text { Background } \\
\text { luminance }\end{array}$ \\
\hline $\begin{array}{l}\text { Norren et al. } \\
{[11,12]}\end{array}$ & $441 \mathrm{~nm}$ (interference filter) & Not stated & Not stated & $\begin{array}{l}\text { Yellow } \\
\qquad>530 \mathrm{~nm})\end{array}$ & $3.0-6.0 \log \mathrm{Td}$ \\
\hline $\begin{array}{l}\text { Yokoyama } \\
\text { et al. [13] }\end{array}$ & $440 \mathrm{~nm}$ (interference filter) & $0.63 \mathrm{~W} / \mathrm{m}^{2}$ & Not stated & Yellow & $13 \mathrm{Wm}^{2}$ \\
\hline $\begin{array}{l}\text { Miyake et al. } \\
\text { [14] }\end{array}$ & $440 \mathrm{~nm}$ (interference filter) & $7.58 \mu \mathrm{W} / \mathrm{cm}^{2}$ & 3 & Yellow & $204 \mu \mathrm{W} / \mathrm{cm}^{2}$ \\
\hline $\begin{array}{l}\text { Gouras et al. } \\
{[2,3]}\end{array}$ & $450 \mathrm{~nm}$ (Wratten 98) & approximately $0.02 \mu \mathrm{W}$ & 5.1 & White & $\begin{array}{r}>5000-9000 \mathrm{Td} \\
\quad\left(>100 \mathrm{~cd} / \mathrm{m}^{2}\right)\end{array}$ \\
\hline $\begin{array}{l}\text { Yamamoto } \\
\text { et al. }[15,16]\end{array}$ & $450 \mathrm{~nm}$ (Wratten 98) & $\begin{array}{l}\text { Xenon flash of } 5.0 \mathrm{~cd} \mathrm{~s} \mathrm{~m}^{-2} \\
\text { and Wratten } 98\end{array}$ & 5 & White & $\begin{array}{l}1.7 \log \mathrm{cd} \mathrm{m}^{-2} \\
\quad\left(50 \mathrm{~cd} \mathrm{~m}^{-2}\right)\end{array}$ \\
\hline $\begin{array}{l}\text { Horiguchi } \\
\text { et al. [17] }\end{array}$ & $450 \mathrm{~nm}$ (LED) & $\begin{array}{l}\text { Long flash of } 2.8 \log \mathrm{Td} \\
\quad\left(12.6 \mathrm{~cd} \mathrm{~m}^{-2}\right)\end{array}$ & 3 & $\begin{array}{c}\text { Wratten } 12 \\
\text { (Yellow) }\end{array}$ & $\begin{array}{l}4.8 \log \mathrm{Td} \\
\quad\left(=1262 \mathrm{~cd} \mathrm{~m}^{-2}\right)\end{array}$ \\
\hline $\begin{array}{l}\text { Simonsen } \\
\text { et al. [18] }\end{array}$ & 440 nm (Wratten 98) & $\begin{array}{l}\text { Xenon flash of } 2.1 \mathrm{~cd} \mathrm{~s} \mathrm{~m}^{-2} \\
\text { and Wratten } 98\end{array}$ & 4 & Yellow & $100 \mathrm{~cd} \mathrm{~m}^{-2}$ \\
\hline Arden et al. [4] & $440 \mathrm{~nm}$ (LED) & $\begin{array}{l}0.3-1.5 \log \mathrm{Td}-\mathrm{s} \\
\quad\left(=0.04-0.6 \mathrm{~cd} \mathrm{~s} \mathrm{~m}^{-2}\right)\end{array}$ & Not stated & $\begin{array}{l}610 \mathrm{~nm} \\
\quad \text { (orange) }\end{array}$ & $\begin{array}{l}18,900 \mathrm{Td} \\
\quad\left(=378 \mathrm{~cd} \mathrm{~m}^{-2}\right)\end{array}$ \\
\hline $\begin{array}{l}\text { Maeda et al. } \\
\text { [19] }\end{array}$ & $450 \mathrm{~nm}$ (Wratten 98) & $\begin{array}{l}\text { Xenon flash of } 5.0 \mathrm{~cd} \mathrm{~s} \mathrm{~m}^{-2} \\
\text { and Wratten } 98\end{array}$ & $5 \mathrm{~Hz}$ & White & 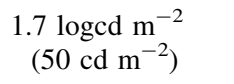 \\
\hline Chiti et al. [20] & $\begin{array}{l}\text { Combination of two filters } \\
\text { of } 430 \text { and } 450 \mathrm{~nm}\end{array}$ & $0.034 \mathrm{~cd} \mathrm{~s} \mathrm{~m}^{2}(=1.71 \mathrm{Td}-\mathrm{s})$ & 2 & Yellow & $\begin{array}{l}10,807 \mathrm{Td} \\
\quad\left(=215 \mathrm{~cd} \mathrm{~m}^{-2}\right)\end{array}$ \\
\hline $\begin{array}{l}\text { Marmor et al. } \\
\text { [21] }\end{array}$ & $440 \mathrm{~nm}$ (LED) & $0.03-0.05 \mathrm{~cd} \mathrm{~s} / \mathrm{m}^{-2}$ & 4 & $\begin{array}{l}590 \mathrm{~nm} \\
\quad \text { (orange) }\end{array}$ & $300 \mathrm{~cd} \mathrm{~m}^{-2}$ \\
\hline $\begin{array}{l}\text { Tsuruoka et al. } \\
\text { [22] }\end{array}$ & $430 \mathrm{~nm}$ (LED) & $\begin{array}{l}0.03 \mathrm{~cd} \mathrm{~s} \mathrm{~m}^{-2}(-1.5 \mathrm{log} \\
\left.\mathrm{cd} \mathrm{s} \mathrm{m}^{-2}\right)\end{array}$ & $1-5$ & White & $\begin{array}{l}2.0 \log \mathrm{cd} \mathrm{m}^{-2} \\
\quad\left(100 \mathrm{~cd} \mathrm{~m}^{-2}\right)\end{array}$ \\
\hline Audo et al. [5] & $445 \mathrm{~nm}$ (LED) & $\begin{array}{l}0.08-0.8 \mathrm{~cd} \mathrm{~s} \mathrm{~m}^{-2}\left(80 \mathrm{~cd} \mathrm{~m}^{-2}\right. \\
\text { with } 1-10 \mathrm{~ms} \text { flashes })\end{array}$ & Not stated & $\begin{array}{l}620 \mathrm{~nm} \\
\quad \text { (orange) }\end{array}$ & $560 \mathrm{~cd} \mathrm{~m}^{-2}$ \\
\hline $\begin{array}{l}\text { Sustar et al. } \\
{[6],[23]}\end{array}$ & 449 nm (Wratten 47B) & $0.016-0.125 \mathrm{~cd} \mathrm{~s} \mathrm{~m}^{-2}$ & 2 & $\begin{array}{l}594 \mathrm{~nm} \\
\quad(\text { amber })\end{array}$ & $100 \mathrm{~cd} \mathrm{~m}^{-2}$ \\
\hline $\begin{array}{l}\text { Rocha-Sousa } \\
\text { et al. [24] }\end{array}$ & $440 \mathrm{~nm}$ & $65 \mathrm{~cd} \mathrm{~m}^{-2}, 10 \mathrm{~ms}$ & Not stated & $\begin{array}{l}660 \mathrm{~nm} \\
\quad \text { (orange) }\end{array}$ & $350 \mathrm{~cd} \mathrm{~m}^{-2}$ \\
\hline $\begin{array}{l}\text { Cima et al. } \\
{[25]}\end{array}$ & 449 nm (Wratten 47B) & $0.016 \mathrm{~cd} \mathrm{~s} \mathrm{~m}^{-2}$ & 2 & $\begin{array}{l}594 \mathrm{~nm} \\
\quad \text { (amber) }\end{array}$ & $100 \mathrm{~cd} \mathrm{~m}^{-2}$ \\
\hline $\begin{array}{l}\text { Schatz et al. } \\
\text { [26] }\end{array}$ & $470 \mathrm{~nm}$ (LED) & $0.1-0.5 \mathrm{~cd} \mathrm{~s} \mathrm{~m}^{-2}$ & Not stated & $\begin{array}{l}594 \mathrm{~nm} \\
\quad \text { (amber) }\end{array}$ & $500 \mathrm{~cd} \mathrm{~m}^{-2}$ \\
\hline $\begin{array}{l}\text { Campi et al. } \\
\text { [27] }\end{array}$ & blue $445 \mathrm{~nm}$ & $0.4 \mathrm{~cd} \mathrm{~s} \mathrm{~m}^{-2}$ & 1 & $\begin{array}{l}600 \mathrm{~nm} \\
\quad \text { (orange) }\end{array}$ & $560 \mathrm{~cd} \mathrm{~m}^{-2}$ \\
\hline $\begin{array}{l}\text { Littink et al. } \\
{[8]}\end{array}$ & Blue (445 nm) (LED) & $2.0 \mathrm{~cd} \mathrm{~s} \mathrm{~m}^{-2}$ & Not stated & $\begin{array}{l}594 \mathrm{~nm} \\
\quad \text { (amber) }\end{array}$ & $15 \mathrm{~cd} \mathrm{~m}^{-2}$ \\
\hline
\end{tabular}


c. Strength of the test flash

Laboratories that use backgrounds of $300 \mathrm{~cd} \mathrm{~m}^{-2}$ have used flashes of low strength, $0.03-0.05 \mathrm{~cd} \mathrm{~s} \mathrm{~m}^{-2}$, while laboratories using bright backgrounds of about $500 \mathrm{~cd} \mathrm{~m}^{-2}$ use stronger flashes, $0.1-0.5 \mathrm{~cd} \mathrm{~s} \mathrm{~m}^{-2}$, in order to elicit robust S-cone mediated responses (Table 1). Weak flashes may be more selective but elicit responses of relatively low amplitude (Fig. 1), whereas stronger stimuli may be difficult for some patients to tolerate.

d. Units of flash strength and luminance

It is acknowledged that the strength of the colored flash requires consideration of the spectral sensitivity of the eye and is accurately described by radiant energy (Watts $/$ steradian $/ \mathrm{m}^{2} / \mathrm{nm}$ ), but for uniformity of clinical use and consistency with other brief flash stimuli, strength is defined in this protocol in units of $\mathrm{cd} \mathrm{s} \mathrm{m}{ }^{-2}$. For stimulus durations $>10 \mathrm{~ms}$, stimulus strength is given in units of luminance $\left(\mathrm{cd} \mathrm{m}^{-2}\right)$.

\section{Calibration}

Calibration in accordance with the ISCEV standard ERG is recommended [1]. A spectral photometer is required to determine the spectral characteristics of the short-wavelength flash. Care should be taken to measure a range of flash luminance levels as some Ganzfeld stimulators use different combinations and banks of LEDs for different luminance ranges, and these may have different wavelength specifications.

\section{Protocol specifications}

Patient preparation follows that for the current ISCEV standard ERG [1]. For routine applications, the S-cone ERG protocol may be added to the ISCEV standard protocol after the other LA ERGs. Additional specifications are outlined in Table 1.

a. Spectral characteristics and luminance of the background.

The background peak wavelength is between 570 and $620 \mathrm{~nm}$ (yellow, amber, orange). The background luminance is $300 \mathrm{~cd} \mathrm{~m}^{-2}$. Recordings obtained using higher luminance backgrounds may be added (see section c). b. Spectral characteristics of the test flash

For routine clinical diagnostics, LEDs with peak wavelength of between $450 \mathrm{~nm}$ and $470 \mathrm{~nm}$ are specified. If Xenon flashes and filters are used, a blue filter (Kodak \#98 with peak transmission at $450 \mathrm{~nm}$ ) is used. The method of stimulation (LED or optical filter) and the peak wavelength and bandwidth at half-height of the stimulus should be stated.

c. Stimulus strength

The minimum S-cone ERG protocol includes a stimulus strength of $0.05 \mathrm{~cd} \mathrm{~s} \mathrm{~m}^{-2}$ delivered on a background luminance of $300 \mathrm{~cd} \mathrm{~m}^{-2}$. This does not preclude the recording of additional S-cone ERGs or an S-cone ERG stimulus-response series, e.g., stimuli ranging from approximately 0.025 to $0.2 \mathrm{~cd} \mathrm{~s} \mathrm{~m}^{-2}$ (see Fig. 1). Additional stronger flashes (e.g., $0.1-0.5 \mathrm{~cd} \mathrm{~s} \mathrm{~m}^{-2}$ ) on a brighter background luminance (e.g., 500-560 $\mathrm{cd} \mathrm{m}^{-2}$ ) can be used but may be difficult for some patients to tolerate.

d. Flash duration and frequency of presentation Flash duration should be equal or less than $5 \mathrm{~ms}$. The presentation rate is $2 \mathrm{~Hz}$ (inter-stimulus interval $0.5 \mathrm{~s}$ ) as for the ISCEV standard LA3ERG.

e. Signal averaging

Small responses to dim flashes or abnormally reduced S-cone ERG components may require signal averaging of up to several hundred recordings.

\section{f. Duration of light adaptation}

When the S-cone ERG protocol is embedded in the full-field ERG protocol and conducted as a continuation of the light-adapted ERG recording, then the 10 min adaptation to the light-adapted background (white light $30 \mathrm{~cd} \mathrm{~m}^{-2}$ ) is sufficient before starting to record the S-cone ERG. However, if the S-cones ERG protocol is used as a stand-alone protocol, light adaptation to the background should proceed for $10 \mathrm{~min}$ before starting to record the S-cone ERG.

\section{Response evaluation}

The waveform is evaluated as having a single or double peak. If there are two peaks, the peak time is measured from stimulus onset to the 2nd (S-conemediated) peak. Amplitude is measured from baseline to the peak or from the trough that follows the 1 st peak 


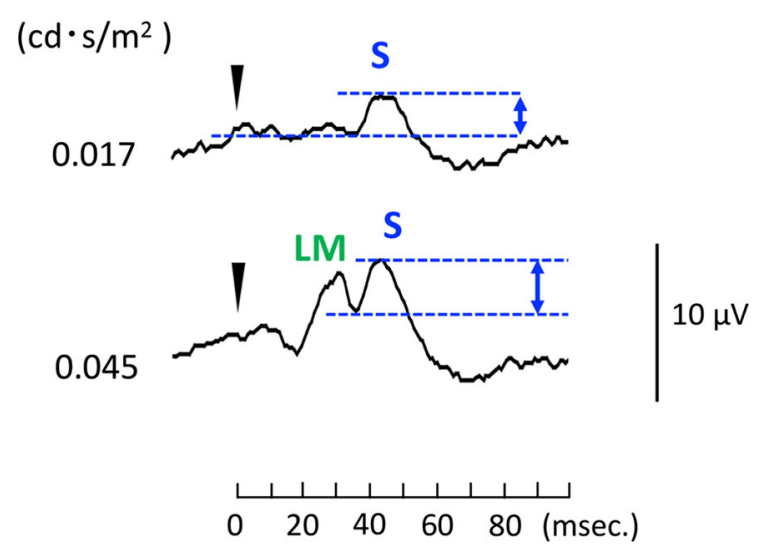

Fig. 2 Measuring the amplitude of the S-cone ERG in a response to a dim stimulus that contains only one peak and in a response to a stimulus of moderate strength that contains 2 peaks, the first is the L/M-cone ERG and the second the S-cone ERG. Amplitude is measured from the trough preceding the S-cone ERG peak (lower and upper horizontal dashed blue lines, respectively)

to the peak of the following positive wave depending upon response waveform (Fig. 2).

\section{Reporting}

Reporting the S-cone ERG should follow the recommendations of the ISCEV standard ERG [1]. The spectral characteristics of the stimulus and background should be specified. The strength and duration of the light stimulus and the luminance of the background should be stated. The presence or absence of a 2-peak ERG pattern should be acknowledged, and amplitude and peak time of the 2nd peak should be reported as S-cone ERG along with age-appropriate laboratory reference data. If not already documented as part of the ISCEV standard ERG, pupil diameters following mydriasis should be documented. It is acknowledged that for routine diagnostic reporting it may be enough to describe the S-cone ERG qualitatively.

\section{Compliance with ethical standards}

Conflict of interest All authors declare that they have no conflict of interest.

Statements of human rights The procedures that were used to obtain the data shown in figures 1 and 2, adhered to the tenents of the Word Medical Association Declaration of Helsinki.
Statement on the welfare of animals Not applicable.

Informed consent A written informed consent was signed by the subjects after they were provided with sufficient information on the procedures to be used.

Open Access This article is distributed under the terms of the Creative Commons Attribution 4.0 International License (http:// creativecommons.org/licenses/by/4.0/), which permits unrestricted use, distribution, and reproduction in any medium, provided you give appropriate credit to the original author(s) and the source, provide a link to the Creative Commons license, and indicate if changes were made.

\section{Appendix: Justification for the protocol details and excluded methods}

A literature review was performed with PubMed search to find the publications that reported recordings of S-cone ERG using the following keywords: (S-cone or blue-cone) and (electroretinogram or ERG). Only the reports of S-cone ERG using a blue flash on strong adapting background illumination to suppress $\mathrm{M}$ - and L-cone activities were extracted. Animal studies were excluded, as well as studies using focal types of stimulation. Reports of S-cone ERG recording using silent substitution methods were also excluded. Studies from the year 1970 to 2018 were reviewed, and those with specified stimulus parameters are summarized in Table 1.

\section{References}

1. McCulloch DL, Marmor MF, Brigell MG, Hamilton R, Holder GE, Tzekov R, Bach M (2015) ISCEV Standard for full-field clinical electroretinography (2015 update). Doc Ophthalmol 130:1-12

2. Gouras P, MacKay CJ (1990) Electroretinographic responses of the short-wavelength-sensitive cones. Invest Ophthalmol Vis Sci 31:1203-1209

3. Gouras P, MacKay CJ, Yamamoto S (1993) The human S-cone electroretinogram and its variation among subjects with and without $\mathrm{L}$ and $\mathrm{M}$-cone function. Invest Ophthalmol Vis Sci 34:2437-2442

4. Arden G, Wolf J, Berninger T, Hogg CR, Tzekov R, Holder GE (1999) S-cone ERGs elicited by a simple technique in normal and in tritanopes. Vis Res 39:641-650

5. Audo I, Michaelides M, Robson AG, Hawlina M, Vaclavik V, Sanbach JM, Neveu MM, Hogg CR, Hunt DM, Moore AT, Bird AC, Webster AR, Holder GE (2008) Phenotypic variations in enhanced S-cone syndrome. Invest Ophthalmol Vis Sci 49:2082-2093 
6. Sustar M, Perovsek D, Cima I, Stirn-Kranjc M, Hawlina M, Brecelj J (2015) Electroretinography and optical coherence tomography reveal abnormal post-receptoral activity and altered retinal lamination in patients with enhanced S-cone syndrome. Doc Ophthalmol 130:165-177

7. Newman H, Blumen SC, Braverman I, Hanna R, Tiosano B, Perlman I, Ben-Yosef T (2016) Homozygosity for a recessive loss-of-function mutation of the NRL gene is associated with a variant of enhanced S-cone syndrome. Invest Ophthalmol Vis Sci 57:5361-5371

8. Littink KW, Stappers PTY, Riemslag FCC, Talsma HE, van Genderen KM, Cremers FPM, Collin RWJ, van den Born LI (2018) Autosomal recessive NRL mutations in patients with enhanced s-cone syndrome. Genes 9:E68. https://doi.org/ 10.3390/genes9020068

9. Kamiyama M, Yamamoto S, Nitta K, Hayasaka S (1996) Undetectable $\mathrm{S}$ cone electroretinogram b-wave in complete congenital stationary night blindness. $\mathrm{Br} \mathrm{J}$ Ophthalmol 80:637-639

10. McBain VA, Egan CA, Pieris SJ, Supramaniam G, Webster AR, Bird AC, Holder GE (2005) Functional observations in vitamin A deficiency: diagnosis and time-course of recovery. Eye 21:367-376

11. Norren DV, Padmos P (1973) Human and macaque blue cones studied with electroretinography. Vision Res $13: 1241-1254$

12. Padmos P, van Norren D, Faijer JW (1978) Blue cone function in a family with an inherited tritan defect, tested with electroretinography and psychophysics. Invest Ophthalmol Vis Sci 17:436-441

13. Yokoyama M, Yoshida T, Ui K (1973) Spectral responses in the human electroretinogram and their clinical significance. Jpn J Ophthalmol 17:113-124

14. Miyake Y, Yagasaki K, Ichikawa H (1985) Differential diagnosis of congenital tritanopia and dominantly inherited juvenile optic atrophy. Arch Ophthalmol 103:1496-1501

15. Yamamoto S, Kataoka Y, Kamiyama M, Hayasaka S (1995) Nondetectable S-cone electroretinogram in a patient with crystalline retinopathy. Doc Ophthalmol 90:221-227

16. Yamamoto S, Hayashi M, Takeuchi S, Shirao Y, Kita K, Kawasaki K (1997) Normal S cone electroretinogram b-wave in Oguchi's disease. Br J Ophthalmol 81:1043-1045

17. Horiguchi M, Miyake Y, Kondo M, Suzuki S, Tanikawa A, Koo HM (1995) Blue light-emitting diode built-in contact lens electrode can record human S-cone electroretinogram. Invest Ophthalmol Vis Sci 36:1730-1732
18. Simonsen SE, Rosenberg T (1995-1996) Reappraisal of a short-wavelength-sensitive (S-cone) recording technique in routine clinical electroretinography. Doc Ophthalmol 91:323-332

19. Maeda H, Nakamura M, Negi A (2001) Selective reduction of the S-cone component of the electroretinogram in Posner-Schlossman syndrome. Eye (Lond) 15:163-167

20. Chiti Z, North RV, Mortlock KE, Drasdo N (2003) The S-cone electroretinogram: a comparison of techniques, normative data and age-related variation. Ophthalmic Physiol Opt 23:370-376

21. Marmor MF, Cabael L, Shukla S, Hwang JC, Marcus M (2004) Clinical S-cone ERG recording with a commercial hand-held full-field stimulator. Doc Ophthalmol 109:101-107

22. Tsuruoka M, Yamamoto S, Ogata K, Hayashi M (2004) Built-in LED contact lens electrode for S-cone electroretinographic recordings. Doc Ophthalmol 108:61-66

23. Sustar M, Hawlina M, Brecelj J (2011) Electroretinographic evaluation of the retinal S-cone system. Doc Ophthalmol 123:199-210

24. Rocha-Sousa A, Hayashi T, Gomes NL, Penas S, Brandao E, Rocha P, Urashima M, Yamada H, Tsuneoka H, FalcaoReis F (2011) A novel mutation (Cy83Tyr) in the second zinc finger of NR2E3 in enhanced C-cones syndrome. Gaefes Arch Clin Exp Ophthalmol 249:201-208

25. Cima I, Brecelj J, Sustar M, Coppieters F, Leroy BP, De Baere E, Hawlina M (2012) Enhanced S-cone syndrome with preserved macular structure and severely depressed retinal function. Doc Ophthalmol 125:161-168

26. Schatz A, Dominik Fischer M, Schommer K, Zrenner E, Bartz-Schmidt KU, Gekeler F, Willmann G (2014) Attenuation of S-cone function at high altitude assessed by electroretinography. Vis Res 97:59-64

27. Campi I, Cammarata G, Bianchi Marzoli S, Beck-Peccoz P, Santarsiero D, Dazzi D, Bottari de Castello A, Taroni EG, Viola F, Mian C, Watutantrige-Fernando S, Pelusi C, Muzza M, Maffini MA, Persani L (2017) Retinal photoreceptor functions are compromised in patients with resistance to thyroid hormone syndrome (RTH $\beta)$. J Clin Endocrinol Metab 102:2620-2627

Publisher's Note Springer Nature remains neutral with regard to jurisdictional claims in published maps and institutional affiliations. 